\title{
Hepatoprotective Effect of Curcumin and Capsaicin against Lipopolysaccharide Induced Liver Damage in Mice
}

\author{
Thriveni Vasanthkumar', Manjunatha Hanumanthappa ${ }^{1}$, Prabhakar BT², Santhosh Kondajji Hanumanthappa ${ }^{1}$
}

\section{Thriveni Vasanthkumar', Manjunatha Hanuman- thappa', Prabhakar BT ${ }^{2}$, Santhosh Kondajji Hanu- manthappa ${ }^{1}$ \\ 'Department of Biotechnology, Ku- vempu University, Shankaraghatta - 577 \\ 451 Shimoga, Karnataka (St), INDIA. ${ }^{2}$ Molecular biomedicine laboratory, Postgraduate department of studies and research in biotechnology, Sahyadri science college, Kuvempu University, Shimoga-577203, Karnataka (St), INDIA.}

\section{Correspondence}

Manjunatha Hanumanthappa

Assistant professor, Department of Biotechnology, Jnana Sahyadri, Kuvempu University, Shankaraghatta - 577 451, Shimoga, Karnataka, INDIA.

Phone no: +91 8762661348

E-mail: manjunatha75@gmail.com (Primary) manjunathh@kuvempu.ac.in (secondary)

History

- Submission Date: 19-06-2017:

- Review completed: 27-07-2017;

- Accepted Date: 31-08-2017

DOI : 10.5530/pj.2017.6.148

Article Available online http://www.phcogj.com/v9/i6

\section{Copyright}

(C) 2017 Phcog.Net. This is an openaccess article distributed under the terms of the Creative Commons Attribution 4.0 International license.

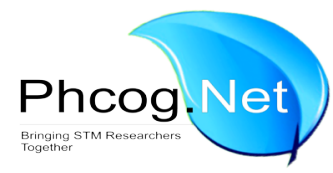

\begin{abstract}
Objective: The present study was undertaken to evaluate the possible ameliorative role of curcumin, capsaicin and their combination against lipopolysaccharide (LPS) induced hepatic toxicity in mice. Methods: Animals were distributed into five experimental groups: Normal control, vehicle control, curcumin, capsaicin and combined curcumin and capsaicin treatment groups respectively, for 7 days prior to LPS induced liver toxicity ( $3 \mathrm{mg} / \mathrm{kg}$ b.w. in saline). Hepatoprotective effect of individual and combined spice principles were evidenced by the measurement of serum marker enzyme activities such as, SGPT, ALP andTB and it was further confirmed by histopathological observation of liver tissue section. Results: The administration of LPS increased serum nonspecific enzymes (SGOT; 174.2 $\pm 3.79 \mathrm{IU} / \mathrm{L}$, SGPT; $124.0 \pm 3.14$ IU/L, ALP; $320.15 \pm 3.88 \mathrm{IU} / \mathrm{L}$ and total bilirubin level; $2.32 \pm 1.23 \mathrm{mg} / \mathrm{dL}$ ), however dietary curcumin and capsaicin decreased the activities of these non-specific serum enzymes including total bilirubin indicating amelioration of the severe LPS induced hepatotoxicity, while the combined spice principles were more significant as shown by the levels of enzymes activities SGOT; $89.9 \pm 1.39 \mathrm{IU} / \mathrm{L}, \mathrm{SGPT} ; 85.9 \pm 1.83 \mathrm{IU} / \mathrm{L}, \mathrm{ALP} ; 138.4 \pm 2.05 \mathrm{IU} / \mathrm{L}$ including total bilirubin level; $0.86 \pm 0.03 \mathrm{mg} / \mathrm{dL}$. Conclusion: Dietary curcumin and capsaicin individually are protective to LPS induced hepatotoxicity, the beneficial effect was found to be more when the two compounds were fed in combination.
\end{abstract}

Key words: Hepatoprotective Activity, Lipopolysaccharide, Curcumin, Capsaicin, SGOT, SGPT, ALP.

\section{INTRODUCTION}

Liver diseases have become one of the major causes for morbidity and mortality in all over the world. Liver cirrhosis is a significant cause of global health burden, with more than one million deaths in 2010. According to WHO report globally alcohol consumption is estimated to cause from $20 \%$ to $50 \%$ of liver cirrhosis and 325 million people were living with chronic hepatitis infections (HBV or HCV) worldwide and 1.34 million people died of viral hepatitis in 2015. ${ }^{1}$ According to the medical certification of cause of death reports 2014, India ranks 61 position in the world ranking list with $68.1 \%$ of deaths due to liver diseases. ${ }^{2}$ William Bernal et al., (2013) reported that, in India $61 \%$ of acute liver failure was due to viral infections (Hepatitis $\mathrm{A}, \mathrm{B}$, and $\mathrm{E}$ ), $7 \%$ was due to others and $31 \%$ of liver injury was due to unknown reasons. ${ }^{3}$ Hepatotoxicity due to drug abuse to be the most common contributing factor for acute liver injury/failure in developed countries, where $53 \%$ and $68 \%$ of acute liver failure were documented in United States and United Kingdom respectively. Whereas, $1 \%$ drug induced liver damage was reported in India. ${ }^{3-5}$

Liver is the body's most complex and largest organ in the body. It plays a major role in maintenance of internal environment, site of immune tolerance while initiating an adequate immune response to infectious agents, thereby acts as a primary line of defense in mucosal immunobiology. As an essential interface between the environment and the internal milieu, liver is continuously exposed to toxic effluents, drug metabolites, and infectious agents ${ }^{6}$ etc. causing liver illness.

LPS is an outer membrane component of gram negative bacteria and widely used model to study the hepatic injury in vitro and in vivo. LPS induces the activation of kupffer cells, which initiates detoxification by removing of some polysaccharide moieties, which is then presented to hepatocytes for further metabolism..$^{7-9}$ However high concentration of LPS overwhelm the detoxification process by activating kupffer cells to release chemo-attractants, leukotrienes, interleukins and complement proteins which stimulate neutrophils and expression of adhesion molecules, ${ }^{10,11,12}$ thereby activating hepatic macrophages to initiate lipid peroxidation, platelet aggregation, microthrombosis, consumptive coagulopathy and blocks sinusoids, results in the disturbance in microcirculation, cell injury and further tissue damage/sclerosis. ${ }^{12-14}$

Cite this article: Thriveni V, Manjunatha $H$, Santhosh KH. Hepatoprotective Effect of Curcumin and Capsaicin against Lipopolysaccharide Induced Liver Damage in Mice. Pharmacog J. 2017;9(6):947-51. 
Many reports have emphasized on the importance of the interactions between nutrition and liver health, including the slowing down of liver damage especially fatty liver, chemicals and infectious agents-induced liver damage. ${ }^{15,16,17}$ Spices are nutraceuticals which have been used since ancient times as predominant class of food adjuncts not only to enhance the taste, colour, flavor of foods and beverages but also for their preservative and medicinal properties. Dietary spice principles curcumin, capsaicin and eugenol were proven to be effective antioxidative agents, cuminaldehyde, piperine, linalool and zingerone were found to be lipid peroxidation inhibitors ${ }^{18}$ by enhancing the activity of endogenous antioxidant enzymes and by quenching oxygen free radicals. ${ }^{19,20}$ Dietary curcumin, capsaicin and garlic were protective against oxidative damage to erythrocytes and liver of hyperlipidemic/hypercholesterolemic rats. ${ }^{21,22}$ Curcumin and capsaicin are protective to iron induced hepatotoxicity, where deposition of iron in hepatic parenchymal cells results in fibrosis and cirrhosis which was measured in terms of lipid peroxidation and elevated levels of plasma alanine aminotransferase, aspartate aminotransferase and lactate dehydrogenase. These beneficial effects were found to be more when the two compounds were fed in combination. ${ }^{23,24}$ In view of the above-mentioned beneficial effects of curcumin and capsaicin, the present study was further aimed to evaluate the potential hepatoprotective activity of individual and combined curcumin and capsaicin against LPS induced hepatotoxicity in mice.

\section{MATERIALS AND METHODS}

\section{Chemicals}

Dietary curcumin, capsaicin and lipopolysaccharide were procured from Sigma-Aldrich (USA). The assay kits for SGOT, SGPT, ALP and TB were purchased from Robonik (India) Pvt. Ltd., (Mumbai, India). All other chemicals used were of analytical grade.

\section{Animals}

Adult male albino mice, weighing 25-30 g housed in individual stainless steel cages, were maintained on standard pellet diet with ad libitum water. The animals were maintained under controlled conditions of temperature with $12 \mathrm{~h}$ light-dark cycle. The animals were used after an acclimatization period of three days in the laboratory animal house. Animal experiments were carried out taking appropriate measures to minimize pain or discomfort in accordance with the guidelines of the animal ethics laid down by the NIH (USA) regarding the care and use of animals for experimental procedures and with due clearance from the Institute's Animal Ethics Committee CPCSEA (Ref: NCP/IAEC/ CL/07/12/2010-11).

\section{Experimental design}

Animals were fasted for $12 \mathrm{~h}$ and then divided into five groups (6 Animals / Group) as mentioned below.

Group A: Normal control

Group B: Positive control

Group C: Curcumin (20 mg/kg/day p. o)

Group D: Capsaicin (4 mg/kg/day p. o)

Group E: Combined curcumin and capsaicin $(10 \mathrm{mg} / \mathrm{kg}$ curcumin+ $2 \mathrm{mg} / \mathrm{kg}$ capsaicin/day, p. o)

Curcumin and capsaicin were dissolved in olive oil and were administered orally for seven days at respective doses. On the $7^{\text {th }}$ day after 6 hrs of the administration of curcumin, capsaicin and combined curcumin and capsaicin (all the experimental samples) by giving a single dose of LPS dissolved in PBS. At the end of the experiment (LPS administration), all the animals were subjected to fasting for $6 \mathrm{hrs}$ and later sacrificed under mild anesthesia.

Collection and sampling of blood for marker enzymes analysis: Blood samples were collected and centrifuged immediately at $4000 \mathrm{rpm}$ at $4{ }^{\circ} \mathrm{C}$ for $10 \mathrm{~min}$ to collect the serum and subjected for estimation of various biochemical parameters namely SGPT (serum glutamic pyruvic transaminase), SGOT (serum glutamic oxaloacetic transaminase), ALP (alkaline phosphate) and TB (total bilurubin) by using respective kits according to the manufacturer's instructions.

Histological analysis: The liver tissues were removed and fixed in neutralized $4 \%$ paraformaldehyde. Specific lobes were taken, embedded in paraffin, and sectioned at $6 \mu \mathrm{m}$. The sections were treated with xylene to remove paraffin, followed by rehydration with plenty of water. The tissue sections were then stained with hematoxylin and eosin (H\&E) to observe general morphology. Histological changes were evaluated under a light microscope.

\section{Statistical analysis}

Results were expressed as mean \pm SEM, $n=6$. Statistical analysis was performed using one-way ANOVA followed by Dunnett's multiple comparison tests. Data was computed for statistical analysis by using Graph Pad prism 5 (San Deigo, CA). The value $\mathrm{p}<0.01$ was considered as statistically significant.

\section{RESULTS}

Effect of spice principles curcumin, capsaicin and their combination on LPS induced antioxidant enzymes

status

The activity of the serum non-specific enzymes SGOT, SGPT, ALP inluding total bilirubin were increased by 1.12, $0.7,0.84$ and 2.22 fold $(\mathrm{p}<0.001)$ respectively in LPS induced group when compared with normal group. Oral supplementation of curcumin $(20 \mathrm{mg} / \mathrm{kg}$ b.w.), capsaicin $(4 \mathrm{mg} /$ $\mathrm{kg}$ b.w.) and combined curcumin and capsaicin $(20 \mathrm{mg} / \mathrm{kg}+4 \mathrm{mg} / \mathrm{kg}$ b.w.) for 7 days significantly decreased the LPS induced elevation of these non-specific enzymes. The decrease in the release of serum non-specific enzymes SGOT, SGPT, ALP including total bilirubin were $0.26,0.29$, 1.17 and 1.44 fold respectively in curcumin treated group; $0.18,0.34$, 1.134 and 1.20 fold in capsaicin treated group and $0.93,0.44,1.313$ and 1.69 fold in combined curcumin and capsaicin treated group when compared with positive control (Table 1).

\section{Effect of curcumin, capsaicin and their combination on LPS induced liver histological examination}

The sections of liver obtained from the normal control mice showed the characteristic hepatic architecture of the normal central vein and surrounding hepatocytes (Figure 1A). While, the liver sections obtained from negative control group exhibited ballooning degeneration, intense hemorrhage and necrosis in most of the hepatocytes. The portal area exhibited infiltration of inflammatory cells and this infiltrated area divided the hepatic parenchyma into lobules (Figure 1B). Conversely, there were few histopathological alterations detected in the liver sections of the curcumin and capsaicin-treated group although rare ballooning degeneration was observed in the hepatic parenchyma allied with few inflammatory cells infiltration (Figure $1 \mathrm{C}$ and D). Interestingly, the liver sections obtained from the group treated with combined curcumin and capsaicin had normal architecture indicating potential benefit of combined spice principles in nullifying the potential toxicity of LPS to liver (Figure 1E). 
Thriveni et al.: Hepatoprotective Effect of Curcumin and Capsaicin against Lipopolysaccharide

Table 1: Effect of curcumin, capsaicin and their combination on LPS induced Hepatotoxicity in Mice

\begin{tabular}{cccccc}
\hline SL No & Groups & $\begin{array}{c}\text { SGOT } \\
(\mathrm{IU} / \mathrm{L})\end{array}$ & $\begin{array}{c}\text { SGPT } \\
(\mathrm{IU} / \mathrm{L})\end{array}$ & $\begin{array}{c}\text { ALP } \\
(\mathrm{IU} / \mathrm{L})\end{array}$ & $\begin{array}{c}\text { Total bilirubin }(\mathrm{mg} / \\
\mathrm{dL})\end{array}$ \\
\hline 1 & Normal Control & $81.9 \pm 2.82^{* * *}$ & $72.16 \pm 2.20^{* * *}$ & $174.2 \pm 1.6^{* * *}$ & $0.72 \pm 0.14^{* * *}$ \\
2 & Positive control & $174.2 \pm 3.79$ & $124.0 \pm 3.14$ & $320.15 \pm 3.88$ & $2.32 \pm 1.23$ \\
3 & Curcumin & $138.0 \pm 3.30^{* * *}$ & $95.5 \pm 2.42^{* *}$ & $147.2 \pm 1.29^{* *}$ & $0.95 \pm 0.02^{* * *}$ \\
4 & Capsaicin & $147.2 \pm 1.84^{* *}$ & $92.1 \pm 3.98^{* * *}$ & $150.0 \pm 2.09^{* * *}$ & $1.05 \pm 0.3^{* *}$ \\
5 & Cur + Cap & $89.9 \pm 1.39^{* *}$ & $85.9 \pm 1.83^{* *}$ & $138.4 \pm 2.05^{* * *}$ & $0.86 \pm 0.03^{* * *}$
\end{tabular}

Values are expressed as mean \pm SEM of six animals per group. One-way ANOVA was performed followed by Dunnett's multiple comparison tests. The values of ${ }^{\star} \mathrm{p}<0.05,{ }^{* *} \mathrm{p}<0.01$ and ${ }^{* * *} \mathrm{p}<0.001$ were considered as statistically significant.
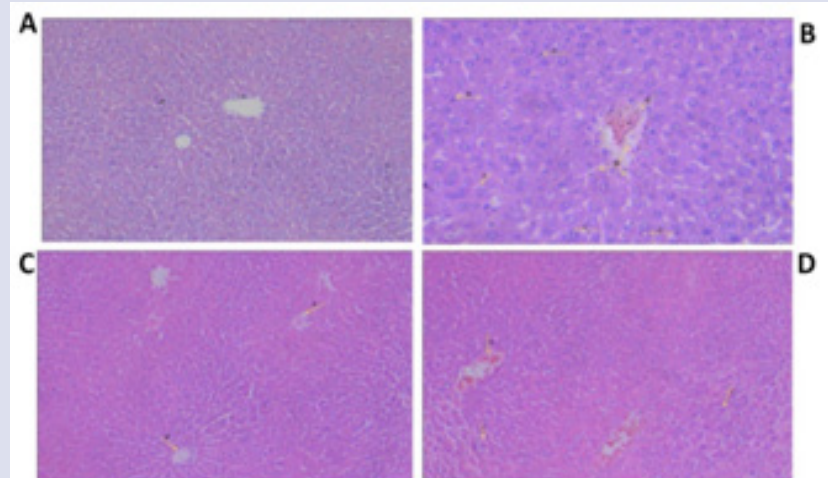

$\mathbf{E}$

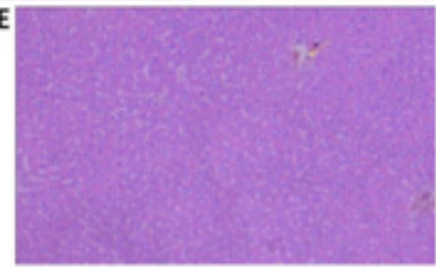

Figure 1: Effect of curcumin, capsaicin and their combination on liver sections stained with $\mathrm{H} \& \mathrm{E}$ in LPS induced injury in mice. Microscopic observation of liver sections of different groups (A) Normal control; (B) Positive control; (C) curcumin treatment group; (D) capsaicin treatment group; (E) curcumin + capsaicin treatment group (a: PMN infiltration; b: Kupffer cell hyperplasia; c: Hepatocytes with hydropic change/disorganized hepatic architecture; d: Disorganized veins).

\section{DISCUSSION}

Drug, chemical or endotoxin induced liver injury represents a major impediment in the modern science. Usually a small dose of LPS triggers non-injurious response, but the subsequent stimuli that are pathologically inert can synergistically enhance the physiological/biochemical response from liver. ${ }^{25}$ Many researchers evaluated the effects of curcumin and capsaicin against $\mathrm{CCl}_{4}$ and drug induced liver toxicity. In addition, the beneficial effect of combined curcumin and capsaicin was proven against iron induced hepatotoxicity. Therefore the present study was designed to evaluate the beneficial influence of dietary curcumin, capsaicin and their combination against LPS induced liver toxicity in mice. Many reports have utilized the analysis of serum non-specific enzymes as a useful tool in estimating the risk of LPS induced liver damage. The cascade of activities initiated by LPS intoxication leads to disruption of structural integrity of the hepatic cell membrane and release of SGOT, SGPT, ALP, lactate dehydrogenase (LDH) and alkaline phosphatase (AP) hepatic non-specific enzymes into the blood stream from the affected, necrotic and dead hepatocytes and possible hepatic dysfunction manifested by increased serum total bilirubin, thus producing signs of hepatotoxicity. ${ }^{26,27}$ In the present study, the observation of elevated level of serum SGOT, SGPT, ALP and total bilirubin in the group of mice treated with LPS alone is consistent with these reports and might explain the inflammation manifested in liver.

Earlier reports state that supplementation of natural antioxidants were proven to be an excellent prevention strategy for many diseases, including diabetes liver injury, liver fibrosis, cancer and ageing. ${ }^{28-32}$ Natural antioxidants curcumin, capsaicin and their combined form prevented the LPS induced hepatotoxicity in mice model. Administration of curcumin $(20 \mathrm{mg} / \mathrm{kg}$ b.w.) and capsaicin ( $4 \mathrm{mg} / \mathrm{kg}$ b.w.) showed significant detoxification, thereby reduced the leakage of SGOT, SGPT, ALP and total bilirubin from the hepatocytes indicating the inhibition of LPS induced toxicity in mice. These results are in agreement with the earlier reports of Zhanq et al..$^{34}$ (2014) and Abdel et al..$^{33}$ (2012). Where, intraperitoneal administration of curcumin $(200 \mathrm{mg} / \mathrm{kg} \mathrm{b.w})$ and capsaicin $(15,150$ and $1500 \mu \mathrm{g} / \mathrm{kg}$ b.w) significantly reduced the LPS induced liver toxicity respectively. However, combined curcumin and capsaicin $(10 \mathrm{mg} / \mathrm{kg}$ $+2 \mathrm{mg} / \mathrm{kg} \mathrm{b.w}$ ) protective activity is found to be more than individual molecules. Our current findings are consistent with previous reports of Manjunatha et al. (2006), where supplementation of combined curcumin and capsaicin was found to be more protective against iron-induced hepatotoxicity, when compared with the individual curcumin and capsaicin fed animals groups.

Furthermore, histopathological evaluation of liver sections of curcumin, capsaicin and combined curcumin and capsaicin fed animal groups mitigated the LPS induced liver injury by reducing the kupffer cell hyperplasia, polymorphonuclear cells (PMNs) infiltration, disorganization of veins and hepatic architecture when compared with positive control group. However, combined spice principles have shown more effective prevention of LPS induced liver toxicity than individually. These results boast up our earlier report ${ }^{35}$ where treatment of curcumin and capsaicin significantly reduced the acetic acid induced vascular permeability and agar induced leukocyte mobilization in vivo, while the combined curcumin and capsaicin had shown higher protective effect than individual molecules.

\section{CONCLUSION}

The present study suggest that dietary intake of curcumin and capsaicin individually are protective to LPS induced liver injury in vivo, and the beneficial influence was appeared to be higher when the two compounds were fed in combination.

\section{ACKNOWLEDGEMENT}

This work was supported by a grant from Department of Science and Technology-Science and Engineering Research Board (DST-SERB) (SB/ EMEQ-343/2013), Govt. of India, New Delhi. First author (TV) thanks DST-SERB for JRF. Second author (HM) thankful to DST-SERB for 
funding under the program "Empowerment and Equity Opportunities for Excellence in Science".

\section{CONFLICT OF INTEREST}

No conflict of interest.

\section{ABBREVIATION USED}

SGOT: Serum glutamic oxaloacetic transaminase; SGPT: Serum glutamic pyruvic transaminase; ALP: Alkaline phosphate; TB: Total bilirubin; LPS: Lipopolysaccharide; WHO: World health organization; HBV: hepatitis B virus; HCV: hepatitis C virus; NIH: National Institutes of Health; CPCSEA: The Committee for the Purpose of Control and Supervision of Experiments on Animals; $\mathbf{H}$ and $\mathbf{E}$ : Hematoxylin and eosin; SEM: Standard error of the mean; PMNs: Polymorphonuclear cells; $\mathbf{C C L}_{4}$ : Carbon tetrachloride; $\mathbf{L D H}$ : Lactate dehydrogenase; AP: Alkaline phosphatase.

\section{REFERENCES}

1. WHO 14th June 2017. WWW.who.int/hepatitis/en/

2. Report on medical certification of cause of death 2014. Office of the Registrar General, Government of India. 2014. Available from: http://www.censusindia. gov.in/2011-Documents/mccd_Report1/mccd_report_2014.pdf

3. William Bernal MD, Julia Wendon. Acute liver failure. The New England Journal of Medicine. 2013:2525-34.

4. Ostapowicz G, Fontana RJ, Schiødt FV, Larson A, Davern TJ, Han SH, et al. Results of a prospective study of acute liver failure at 17 tertiary care centers in the United States. Annals of internal medicine. 2002;137(12):947-54.

5. Reuben A, Koch DG, Lee WM. Drug-induced acute liver failure: results of a us multicenter, prospective study. Hepatology. 2010;52(6):2065-76.

6. Selmi C, Mackay IR, Gershwin ME. The immunological milieu of the liver. Semin Liver Dis. 2007;27:129-39.

7. Kurokawa S, Ishibashi H, Hayashida K, Tsuchiya Y, Hirata Y, sakaki Y. Kupffer cell stimulation of alpha 2-macroglobulin synthesis in rat hepatocytes and the role of glucocorticoid. Cell Struct Funct. 1987;12:35-42.

8. Hewett JA, Schultze AE, VanCise S, Roth RA. Neutrophil depletion protects against liver injury from bacterial endotoxin. Laboratory investigation; a journal of technical methods and pathology. 1992;66(3):347-61.

9. Hewett JA, Jean PA, Kunkel SL, Roth RA. Relationship between tumor necrosis factor-alpha and neutrophils in endotoxin-induced liver injury. American Journal of Physiology-Gastrointestinal and Liver Physiology. 1993;265(6):G1011-5.

10. Peters T, Karck U, Decker K. Interdependence of tumor necrosis factor, prostaglandin E2, and protein synthesis in lipopolysaccharide-exposed rat Kupffer cells. The FEBS Journal. 1990;191(3):583-9.

11. Portolés MT, Ainaga MJ, Pagani R. The induction of lipid peroxidation by E. col lipopolysaccharide on rat hepatocytes as an important factor in the etiology of endotoxic liver damage. Biochimica et Biophysica Acta (BBA)-General Subjects. 1993;1158(3):287-92.

12. Pagani R, Portoles MT, Arahuetes R, Ainaga MJ, Machin C, Rua C. Comparative in vivo and in vitro models to approach the cellular basis of endotoxic shock. The role of sinusoidal liver cells. Histology and histopathology. 1996;11(3):597-606.

13. Van Bossuyt $H$, Wisse E. Endotoxin injection affects the Kupffer cell morphology in the rat liver. Progress in clinical and biological research. 1988;272:161-71.

14. Van Bossuyt H, Wisse E. Structural changes produced in Kupffer cells in the rat liver by injection of lipopolysaccharide. Cell and tissue research. 1988;251(1):205-14

15. Escott Stump S, Jarratt J, Mahaffie JB. Key trends affecting the dietetics profession and the American Dietetic Association. Journal of Am Diet Assoc.
2002;102(12):1819-39

16. Ismail RS, El Megeid AA, Abdel Moemin AR. Carbon tetrachloride-induced liver disease in rats: the potential effect of supplement oils with vitamins $E$ and $C$ on the nutritional status. German Medical Science. 2009;7:1612-3174.

17. Young IS, Woodside JV. Antioxidants in health and disease. Journal of clinical pathology. 2001;54(3):176-86.

18. Reddy AC, Lokesh BR. Studies on spice principles as antioxidants in the inhibition of lipid peroxidation of rat liver microsomes. Molecular and cellular biochemistry. 1992; 111(1-2):117-24.

19. Reddy AC, Lokesh BR. Studies on the inhibitory effects of curcumin and eugenol on the formation of reactive oxygen species and the oxidation of ferrous iron. Molecular and cellular biochemistry. 1994;137(1):1-8.

20. Reddy AC, Lokesh BR. Alterations in lipid peroxides in rat liver by dietary n-3 fatty acids: modulation of antioxidant enzymes by curcumin, eugenol, and vitamin E. The Journal of Nutritional Biochemistry. 1994;5(4):181-8.

21. Kempaiah, Srinivasan. Antioxidant status of red blood cells and liver in hypercholesterolemic rats fed hypolipidemic spices. International journal for vitamin and nutrition research. 2004;74(3):199-208.

22. Kempaiah RK, Srinivasan K. Influence of dietary curcumin, capsaicin and garlic on the antioxidant status of red blood cells and the liver in high-fat-fed rats. Annals of nutrition and metabolism. 2004;48(5):314-20.

23. Manjunatha $\mathrm{H}$, Srinivasan K. Protective effect of dietary curcumin and capsaicin on induced oxidation of low-density lipoprotein, iron-induced hepatotoxicity and carrageenan-induced inflammation in experimental rats. The FEBS journal. 2006;273(19):4528-37.

24. Manjunatha $H$, Srinivasan K. Hypolipidemic and antioxidant effects of dietary curcumin and capsaicin in induced hypercholesterolemic rats. Lipids. 2007; 42(12):1133-42.

25. Yang SQ, Lin HZ, Lane MD, Clemens M, Diehl AM. Obesity increases sensitivity to endotoxin liver injury: implications for the pathogenesis of steatohepatitis. Proceedings of the National Academy of Sciences. 1997;94(6):2557-62.

26. Sun F, Hamagawa E, Tsutsui C, OnoY, OgiriY, Kojo S. Evaluation of oxidative stress during apoptosis and necrosis caused by carbon tetrachloride in rat liver. Biochimica et Biophysica Acta (BBA)-Molecular Basis of Disease. 2001;1535(2):186-91.

27. lida C, Fujii K, Koga E, Washino Y, Ichi I, Kojo S. Inhibitory effect of dimethy sulfoxide (DMSO) on necrosis and oxidative stress caused by D-galactosamine in the rat liver. Journal of nutritional science and vitaminology. 2007;53(2):160-5.

28. Anandakumar P, Kamaraj S, Jagan S, Ramakrishnan G, Vinodhkumar R, Devaki T. Stabilization of pulmonary mitochondrial enzyme system by capsaicin during benzo (a) pyrene induced experimental lung cancer. Biomedicine \& Pharmacotherapy. 2008;62(6):390-4.

29. Ekambaram G, Rajendran P, Magesh $V$, Sakthisekaran D. Naringenin reduces tumor size and weight lost in N-methyl-N'-nitro-N-nitrosoguanidine-induced gastric carcinogenesis in rats. Nutrition Research. 2008;28(2):106-12.

30. Ismail RS, El-Megeid AA, Abdel-Moemin AR. Carbon tetrachloride-induced liver disease in rats: the potential effect of supplement oils with vitamins $E$ and $C$ on the nutritional status. GMS German Medical Science. 2009;7.

31. Rodrigo R, Guichard C, Charles R. Clinical pharmacology and therapeutic use of antioxidant vitamins. Fundamental \& clinical pharmacology. 2007;21(2):111-27.

32. Wu SJ, Lin YH, Chu CC, TsaiYH, Chao JC. Curcumin or saikosaponin a improves hepatic antioxidant capacity and protects against $\mathrm{CCl} 4$-induced liver injury in rats. Journal of medicinal food. 2008;11(2):224-9.

33. Abdel-Salam OM, Abdel-Rahman RF, Sleem AA, Farrag AR. Modulation of lipopolysaccharide-induced oxidative stress by capsaicin. Inflammopharmacology. 2012;20(4):207-17.

34. Zhang J, Xu L, Zhang L, Ying Z, Su W, Wang T. Curcumin attenuates d-galactosamine/lipopolysaccharide-induced liver injury and mitochondrial dysfunction in mice. The Journal of nutrition. 2014;144(8):1211-8.

35. Thriveni Vasanthkumar, Manjunatha H, Rajesh KP. Anti-inflammatory activity of curcumin and capsaicin augmented in combination. Int J Pharm Pharm Sci. 2017;9(6):145-9. 


\section{GRAPHICAL ABSTRACT}

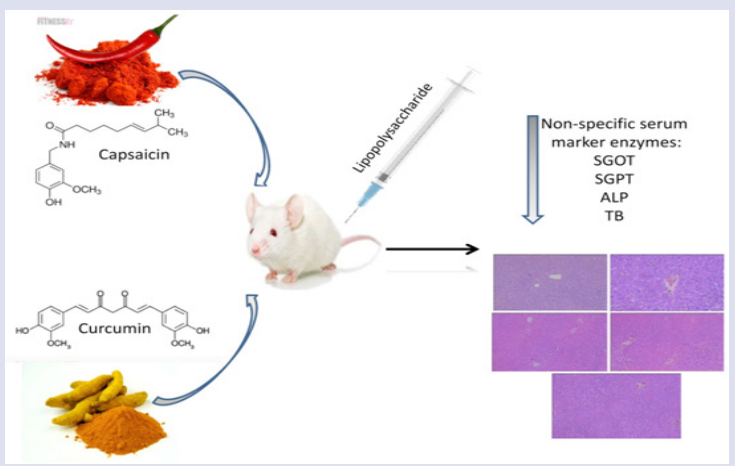

\section{SUMMARY}

- Evaluated health beneficial potency of dietary curcumin and capsaicin against LPS-induced hepatotoxicity in mice.

- Individual and combined curcumin and capsaicin showed protective effect against LPS-induced liver injury by decreasing the elevation of non-specific serum marker enzymes such as SGOT, SGPT, ALP and TB caused by the LPS administration.

- Hepatoprotective effect of combined dietary curcumin and capsaicin was found to be more when compared with individual molecules.

\section{ABOUT AUTHORS}

Thriveni V: Ph.D. Scholar, Department of Biotechnology, Kuvempu University, Shankaraghatta, Shimoga, Karnataka, India.

Dr. Manjunatha H: Assistant Professor, Department of Biotechnology, Kuvempu University, Shankaraghatta, Shimoga, Karnataka, India.

Dr. Santhosh KH: Postdoctoral fellow, Department of Biotechnology, Kuvempu University, Shankaraghatta, Shimoga, Karnataka, India.

Cite this article: Thriveni $\mathrm{V}$, Manjunatha $\mathrm{H}$, Santhosh $\mathrm{KH}$. Hepatoprotective Effect of Curcumin and Capsaicin against Lipopolysaccharide Induced Liver Damage in Mice. Pharmacog J. 2017;9(6):947-51. 